\title{
Superlatent inhibition and spontaneous recovery: Differential effects of pre- and postconditioning CS-alone presentations after long delays in different contexts
}

\author{
R. E. LUBOW \\ Tel-Aviv University, Ramat-Aviv, Israel \\ and \\ L. G. DE LA CASA \\ University of Seville, Seville, Spain
}

\begin{abstract}
In two pairs of three-stage conditioned taste aversion experiments, we examined the effects of delay interval ( 1 or 21 days) between the second and third stages, and of context in which the animals spent the delay (same as or different from the context of the other stages) on latent inhibition (LI) and spontaneous recovery following extinction. In the LI experiments (Experiments $1 \mathrm{~A}$ and $1 \mathrm{~B}$ ), the first stage comprised nonreinforced presentations to saccharin or to water. In the second stage, rats were conditioned by saccharin paired with $\mathrm{LiCl}$. In the extinction experiments (Experiments $2 \mathrm{~A}$ and $2 \mathrm{~B}$ ), the order of the stages was reversed. For all experiments, Stage 3, the test stage, consisted of three presentations of saccharin alone. There was a super-LI effect in the saccharin-preexposed group that spent the 21day delay in the different context (Experiment 1A). When the delay was spent in the same context, there was no difference in the amount of LI between the short- and long-delay groups (Experiment 1B). Conversely, there was a spontaneous recovery effect in the long-delay/same-context group (Experiment 2B), but not in the long-delay/different-context group (Experiment 2A). The pattern of results, incompatible with current explanations of delay-induced changes in memory performance, was interpreted in terms of an interaction between the delay conditions (same or different delay context), which modulate the extinction of previously acquired context-CS-nothing associations (during CS-alone presentations), and primacy effects.
\end{abstract}

Latent inhibition (LI) is most often attributed to some mechanism, operative during the stimulus-preexposure period, that negatively affects subsequent associability of the stimulus when it is paired with an unconditioned stimulus (US; Lubow, Weiner, \& Schnur, 1981; Mackintosh, 1975; Pearce \& Hall, 1980; Wagner, 1981). In opposition to the acquisition-failure account of LI, it has been suggested that LI is a result of competition-based retrieval failure (see, e.g., Bouton, 1993; Miller, Kasprow, \& Schachtman, 1986). As applied to three-stage (preexposure, conditioning, and test) LI procedures, such a hypothesis proposes that, following stimulus preexposure, the acquisition of the new association to the old stimulus proceeds unimpaired. However, in the test stage, when the subject again encounters the target stimulus, two competing associa-

This research was supported by DGES Grant BSO2000-0323-C02-01 from the Spanish government. We thank Raúl Martínez and Clara Fernández for their help in conducting the experiments. Correspondence concerning this article should be addressed either to R. E. Lubow, Department of Psychology, Tel-Aviv University, Ramat-Aviv 69978, Israel (e-mail: lubow@freud.tau.ac.il)or to L. G. De la Casa, Department of Experimental Psychology, C/Camilo José Cela, s/n 41018 Seville, Spain (e-mail: delacasa@us.es). tions are retrieved: the earlier stimulus-no-consequence association from the preexposure stage, and the stimulusUS association from the conditioning stage. In normal LI, the nonpreexposed group exhibits greater conditioned response strength than does the preexposed group because there is only the second association to be retrieved. The stimulus-preexposed group exhibits less conditioned response strength because the first association interferes or competes with the retrieval of the second.

Support for the retrieval/competition theories of LI, and against acquisition-failure theories, comes from LI studies that have obtained better conditioning performance after long as compared with short delays between conditioning and test stages. If LI is found after a short but not after a long delay, and if this difference is due to stronger conditioning performance in the stimulus-preexposed delay group than in the stimulus-preexposed no-delay group, then this is taken as evidence that with the short delay, the conditioned-stimulus (CS)-US association was present but not manifest. Such effects have been reported mainly with conditioned taste aversion (CTA; see, e.g., Aguado, de Brugada, \& Hall, 2001, Experiment 2; Aguado, Symonds, \& Hall, 1994, Experiment 1; Bakner, Strohen, Nordeen, 
\& Riccio, 1991; De la Casa \& Lubow, 1995), albeit not consistently (see, e.g., Álvarez \& López, 1995). Recently, De la Casa and Lubow $(2000,2002)$ obtained greater LI after a long than after a short retention interval. Unlike attenuated LI with long delays, which appears when the delay interval is spent in the same context in which the preexposure, conditioning, and test stages took place, super-LI effects are obtained only when the context of delay is different from the context in which the CS and the US are presented (De la Casa \& Lubow, 2000, 2002).

Neither associability-deficit nor retrieval/competition theories of LI can account for super-LI. Retrieval theories themselves differ in their treatments of interval effects. Riccio has argued that many effects that increase with delays, such as the weakening of a previously acquired discrimination, can be explained by a flattening of stimulusgeneralization gradients over time, the consequence of which would be the loss of differentiation between specific stimulus features (see, e.g., Riccio, Ackil, \& BurchVernon, 1992; Riccio, Rabinowitz, \& Axelrod, 1994; Riccio, Richardson, \& Ebner, 1984). Although it is not clear how Riccio's formulation would apply to the LI-related interval effects, other retrieval/competition theories do address this issue. Bouton (1993; Bouton, Nelson, \& Rosas, 1999) has claimed that the purported retrieval failure that is exhibited after extended retention intervals is the result of such intervals' producing changes of context, internal as well as external. Thus, because LI is relatively context specific, the LI attenuation that results from extended intervals between stages has been attributed to time-induced changes in context. By allowing for extinction of CScontext associations, Miller and Matzel's (1988) comparator hypothesis also accounts for delay-induced LI attenuation. However, neither retrieval nor acquisition-deficit theories provide for an increase in LI as a function of increasing interval length, perhaps, at least in part, because the super-LI effect has been reported only recently (De la Casa \& Lubow, 2000, 2002).

Studies that report LI attenuation with delay and adopt a retrieval/competition account of these effects assume that, in the competition between associations, it is the CSno-consequence association that either is weakened or becomes less retrievable with time (see, e.g., Killcross, Kiernan, Dwyer, \& Westbrook, 1998). If one accepts this position, then an increase in LI with delay (De la Casa \& Lubow, 2000, 2002) would be due to strengthening of the CS-no-consequence association over time or to enhanced retrieval of the preexposure episode. In both cases, the explanatory burdens for both attenuated and super-LI effects focus on the CS-no-consequence association.

However, the procedure for producing LI, which, by definition, requires CS-alone presentations followed by CS-US presentations, necessarily confounds the type of presentation with order of presentation. This is particularly troublesome for explanations of effects in three-stage (preexposure, conditioning, test) LI paradigms that rely on concepts of competition between CS-no-consequence and CS-US associations, given that there is no way to dif- ferentiate between the type of association and the order of presentation in such paradigms.

The same problem exists for the extinction paradigm, but in reverse, because the CS-alone presentations come after, rather than before, the conditioning episode. Thus, spontaneous recovery - that is, the increase of conditioning strength with the passage of time following the CS-alone extinction procedure - is attributed to the facilitated retrieval of the CS-US association, which, in this case, was, again, the first learned association (see, e.g., Rosas \& Bouton, 1996). In short, both super-LI and spontaneous recovery can be described in terms of delay-induced recovery of first associations, CS-no-consequence for LI, and CS-US for spontaneous recovery.

From this one might conclude that order of presentation is a necessary and sufficient condition for predicting delay-induced effects. However, at least for LI, these order effects are disrupted by the nature of the context in which the delay interval is spent. As has been noted, super-LI is obtained only when the delay context is different from the remaining experimental contexts. On the other hand, if all of the contexts, including that of delay, are the same, then $\mathrm{LI}$ is attenuated. One would expect type of interval context to have comparable effects on spontaneous recovery. However, to the best of our knowledge, no such study exists.

By using type of interval context, a variable that differentially affects delay-induced LI (CS-alone presentations in the first position), together with a condition in which the CS-alone presentations are in the second position (extinction procedure), it is possible to gain some understanding of the relative roles of type of stimulus presentation (CS alone vs. CS-US) and order of presentation in producing the various LI and spontaneous recovery effects.

To this end, we conducted two pairs of three-stage CTA experiments, each with a $2 \times 2$ design. In Experiments $1 \mathrm{~A}$ and $1 \mathrm{~B}$, we examined the effects of length of retention interval on LI (stimulus-preexposed vs. -nonpreexposed) when the delay period was spent in a different environment than that in which the CS and US were presented (Experiment 1A) and when all stages were spent in the same environment (Experiment 1B). Experiments 2A and 2B were identical to Experiments $1 \mathrm{~A}$ and $1 \mathrm{~B}$, respectively, except that the positions of the stimulus-exposed (extinction) versus -nonexposed presentations and the CS-US trial were reversed. In Experiments 1A and 1B, CS-alone presentations preceded the conditioning trial, thereby defining an LI procedure; in Experiments $2 \mathrm{~A}$ and 2B, the CS-alone presentations took place after the conditioning trial, thereby defining an extinction procedure.

\section{EXPERIMENTS 1A AND 1B}

\section{Latent Inhibition}

Experiments 1A and 1B used a three-stage, CTA, LI procedure. In Stage 1, one group was preexposed to a saccharin solution (PE) on each of 4 days, and a second group was not preexposed (NPE). In Stage 2, both groups received a saccharin-US conditioning trial. Half of each 
group entered the Stage 3 test 1 day after conditioning, and half 21 days after conditioning. Thus, each of the two experiments comprised a $2 \times 2$ design, with two levels of stimulus preexposure (PE and NPE) and two levels of delay ( 1 day and 21 days).

The two experiments differed from each other in only one respect. In Experiment $1 \mathrm{~A}$, the animals spent the delay period in a context that was different from that in which they had received the CS-alone, CS-US, and test trials. The latter three procedures were conducted in the same experimental cages, and the delay period in the home cage. In Experiment 1B, the entire experiment, including the delay interval, took place in the home cages.

In Experiment 1A, in which there was a different delay context, we expected to find a super-LI effect-namely, more LI (more saccharin solution consumed by the PE group than by the NPE group) in the 21-day delay condition than in the 1-day delay condition (De la Casa \& Lubow, 2000, 2002). In Experiment 1B, in which the delay context was the same, we expected, on the basis of past reports, either attenuated LI in the long-as compared with the short-delay condition (see, e.g., Aguado et al., 2001; Aguado et al., 1994), or no difference in the amount of LI in the two delay conditions (see, e.g., Álvarez \& López, 1995; De la Casa \& Lubow, 2000, Experiment 3B).

\section{Method}

\section{Subjects}

Sixty-four naive adult Wistar rats participated in the experiment, 32 in Experiment $1 \mathrm{~A}$ and 32 in Experiment $1 \mathrm{~B}(n=8$ per group). Mean weight was $334 \mathrm{~g}$ (range, 267-508 g). The animals were housed individually in $40 \times 20 \times 24 \mathrm{~cm}$ Plexiglas cages on a 12:12-h light:dark cycle, with all the experimental sessions occurring during the light period. Standard rat food was continuously available.

\section{Apparatus}

In Experiment 1A, all the experimental manipulations, except for the delay interval, were conducted in an isolated room, different from the vivarium, in which there were eight Plexiglas cages $(30 \times$ $18 \times 18 \mathrm{~cm}$ ) that were used as the experimental context. In Experiment $1 \mathrm{~B}$, all the experimental sessions were conducted in the animals' home cages. All of the subjects from both experiments were housed in the colony room during the delay interval. The remaining equipment was the same for both experiments. Liquid rations were provided at room temperature in 150-ml graduated plastic bottles fitted with stainless steel spouts, similar to those used in the home cages. A bottle was attached to the front of each cage during liquid presentations. The amount of liquid intake was indexed by the difference between bottle weight before and after the liquid presentations. The flavor used for preexposure, conditioning, and test was a $0.04 \%$ sodium saccharin solution. The US was a $0.5 \%$ body-weight i.p. injection of $0.4 \mathrm{M} \mathrm{LiCl}$.

\section{Procedure}

A summary of the experimental designs is shown in the upper section of Table 1. After 7 days on a 23.5-h water-deprivation schedule, which was maintained throughout the experiment except as otherwise indicated, the animals were matched for body weight, and each was assigned to one of eight groups. The first stage was conducted on Days 8-11. Each session lasted $5 \mathrm{~min}$, and all liquid consumption was recorded. Half of the subjects were preexposed to saccharin (PE) and half to water (NPE). The second stage was conducted on Day 12. All of the animals received access to the saccharin solution, followed by i.p. injections of $\mathrm{LiCl}$. Testing was conducted on Days 13-15 for those groups in the 1-day delay condition, and on Days 33-35 for those groups in the 21-day delay condition. On each of the 3 test days, the subjects had access to the saccharin solution. Immediately following each of the 5-min sessions, the animals were returned to their home cages and allowed to drink water for $25 \mathrm{~min}$.

To equate deprivation level for all subjects at the time of testing, water was available ad lib on Days 12-20 to those animals in the 21day delay condition. The water-deprivation schedule was reinstated on Day 21.

Table 1

Experimental Designs for Experiments 1A and 1B (Latent Inhibition) and $2 A$ and $2 B$ (Extinction)

\begin{tabular}{lcllrl}
\hline Procedure & Experiment & Stage 1 & Stage 2 & Interval (days) & Test \\
\hline Latent inhibition & 1A (Diff context) & Sac. & Sac.-US & 1 & Sac. \\
& & Water & Sac.-US & 1 & Sac. \\
& & Sac. & Sac.-US & 21 & Sac. \\
& Water & Sac.-US & 21 & Sac. \\
& \multirow{2}{*}{ 1B (Same context) } & Sac. & Sac.-US & 1 & Sac. \\
& & Water & Sac.-US & 1 & Sac. \\
& & Sac. & Sac.-US & 21 & Sac. \\
& & Water & Sac.-US & 21 & Sac. \\
& 2A (Diff context) $)$ & Sac.-US & Sac. & 1 & Sac. \\
& & Sac.-US & Water & 1 & Sac. \\
& & Sac.-US & Sac. & 21 & Sac. \\
& Sac.-US & Water & 21 & Sac. \\
& 2B (Same context) & Sac.-US & Sac. & 1 & Sac. \\
& & Sac.-US & Water & 1 & Sac. \\
& & Sac.-US & Sac. & 21 & Sac. \\
& Sac.-US & Water & 21 & Sac. \\
\hline
\end{tabular}

Note-In Experiments 1A and 2A, Stages 1,2, and Test were conducted in a context different from that of the delay interval. In Experiments 1B and 2B, all stages, including the delay interval, were conducted in the same context. For LI experiments, Stage 1 saccharin (Sac.) and water were presented over 4 days; for extinction experiments, Stage 2 saccharin and water also were presented over 4 days. 


\section{Results and Discussion}

\section{Experiment 1A (Different Interval Context)}

During the four preexposure trials, the mean amount of saccharin consumed per trial by the PE groups was $8.05 \mathrm{ml}$ $(S D=2.53)$; the NPE groups consumed $8.81 \mathrm{ml}(S D=$ 2.04 ) of water. The mean amount of saccharin consumed by the four groups on the conditioning day was $9.90 \mathrm{ml}$ $(S D=2.33)$ for the NPE/1-day group, $10.44 \mathrm{ml}(S D=$ $1.68)$ for the NPE/21-day group, $10.66 \mathrm{ml}(S D=2.8)$ for the PE/1-day group, and $9.1 \mathrm{ml}(S D=2.6)$ for the PE/21day group. There was no significant difference between groups $[F(3,28)<1]$. All subsequent analyses were conducted on amount of saccharin consumed on the test days, the index of conditioning strength.

Figure 1 ( panel A) presents the mean amount of saccharin consumed on each of the three test trials as a function of preexposure and delay. The data were submitted to a mixed $3 \times 2 \times 2$ analysis of covariance (ANCOVA). The main factors were trials, preexposure (PE vs. NPE), and delay between conditioning and test ( 1 vs. 21 days). The covariate was the amount of saccharin solution consumed on the conditioning trial. As can be seen in Figure 1 ( $p a n e l$ A), all groups increased consumption as a function of trials $[F(2,56)=33.48, p<.001]$. The trials $\times$ preexposure interaction also was significant $[F(2,56)=4.45, p<.05]$, due to a greater increase in consumption across trials for the PE groups than for the NPE groups. None of the other interactions with trials was significant $(F \mathrm{~s}<1)$. As was expected, there was a strong LI effect; the animals in the PE groups drank more than did those in the NPE groups $[F(1,27)=470.29, p<.001]$. The main effect of delay was not significant $[F(1,27)=2.17, p>.15]$. Importantly, the PE/NPE $\times$ delay interaction was significant $[F(1,27)=10.06, p<.01]$.

Figure 1 (panel B) presents mean saccharin consumption, collapsed over all test days, as a function of preexposure and delay. As can be seen in the figure, the source of the preexposure $X$ delay interaction is a super-LI effectmore LI in the PE/21-day group than in the PE/1-day group. This impression was confirmed by a post hoc comparison (Duncan test, alpha set at .05).

\section{Experiment 1B (Same Interval Context)}

During the four preexposure trials, the mean amount of saccharin consumed per trial by the PE groups was $9.52 \mathrm{ml}$ $(S D=1.72)$; the NPE groups consumed $8.78 \mathrm{ml}(S D=$ 1.73 ) of water. On the conditioning day, the mean amount of saccharin solution consumed by the four groups was $13.13 \mathrm{ml}(S D=2.6)$ for the NPE/1-day group, $10.92 \mathrm{ml}$ $(S D=1.93)$ for the NPE/21-day group, $11.53 \mathrm{ml}(S D=$ $3.54)$ for the PE/1-day group, and $13.05 \mathrm{ml}(S D=1.76)$ for the PE/21-day group. There was no significant difference between groups $[F(3,28)=1.49, p>.23]$. Subsequent analyses were conducted on saccharin consumption in the test stage.

Figure 2 (panel A) shows the mean amount of saccharin consumed across the three test trials by PE and NPE groups as a function of delay. As in Experiment 1A, a mixed $3 \times 2 \times 2$ ANCOVA with trials, exposure, and delay as main factors was performed on these data, with amount of saccharin consumed on the conditioning day as a covariate. For all groups, saccharin consumption in-

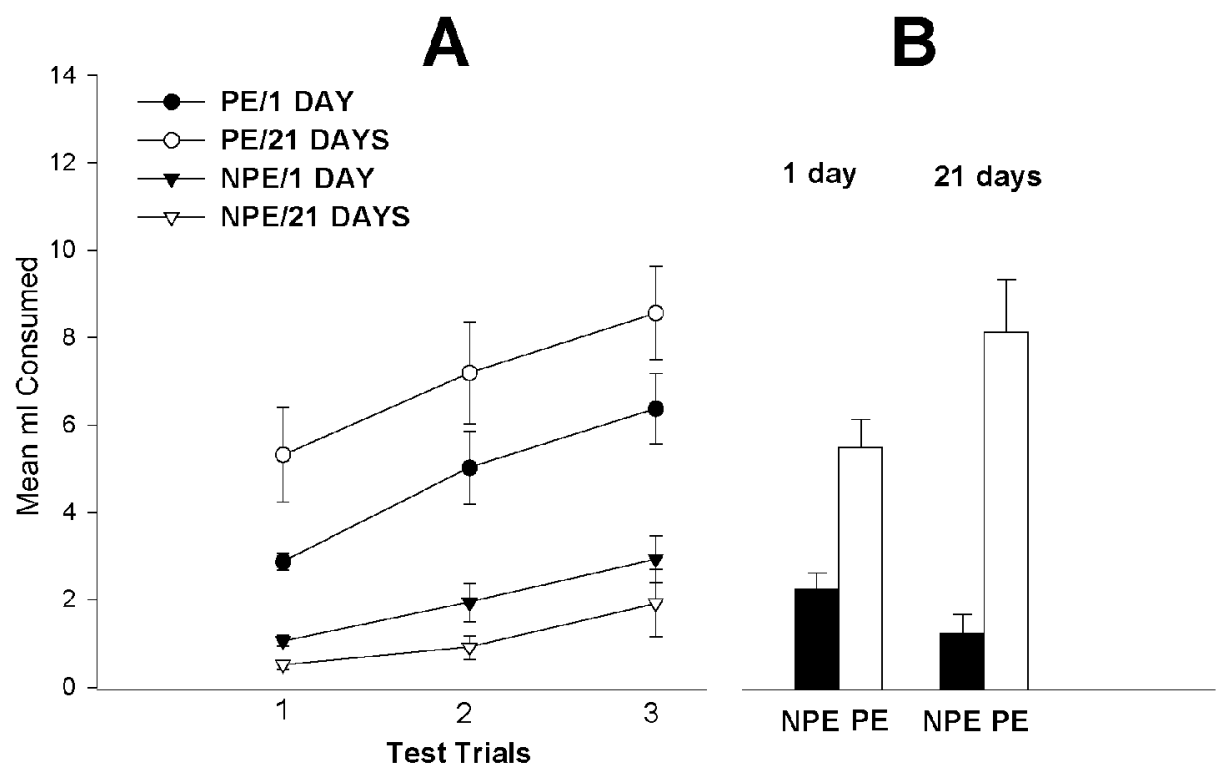

Figure 1. Experiment 1A: Mean amount of saccharin solution consumed by the four groups as a function of the three test trials (panel $A$ ) and averaged across trials (panel B). Vertical bars represent the standard errors of the mean. PE/1 day: flavor preexposed, 1-day delay; PE/21 days: flavor preexposed, 21-day delay; NPE/1 day: not preexposed to flavor, 1-day delay; NPE/21 days: not preexposed to flavor, 21-day delay. 
creased across test trials $[F(2,56)=44.29, p<.001]$. None of the interactions with trials was significant $(p \mathrm{~s}>$ .17). The between-subjects analyses revealed a significant main effect of stimulus preexposure $[F(1,27)=55.72$, $p>.001]$, with the PE groups drinking more saccharin than the NPE groups (i.e., LI). The main effect of delay was not significant $[F(1,27)=1.08, p>.30]$. Finally, and in contrast to the findings of Experiment $1 \mathrm{~A}$, the preexposure $\times$ delay interaction was not significant $[F(1,27)=$ $1.72, p>.20$ ]. As can be seen in Figure 2 (panel B), irrespective of the length of the delay interval, the mean amount of saccharin consumed, averaged over the three test trials, was similar for both PE groups.

\section{Experiments 1A and 1B Compared}

A comparison between Figures 1 and 2 suggests that, in general, test-phase saccharin aversion was stronger with the different as opposed to the same context interval (Experiments $1 \mathrm{~A}$ and $1 \mathrm{~B}$, respectively). Indeed, a complete ANCOVA, ${ }^{1}$ with Experiments $1 \mathrm{~A}$ and $1 \mathrm{~B}$ as a variable, provided a significantmain effect of experiment $[F(1,55)=$ $15.48, p<.001$ ], suggesting that more saccharin was consumed on test trials when the prior delay was spent in the same context than when it was spent in the different context. Relatedly, there was a significant experiment $\times$ trials interaction $[F(2,112)=4.43, p<.05$; see Figures 1 and 2, A panels]. None of the other effects involving experiment was significant.

In summary, Experiment 1A, in which the delay interval was spent in the home cage and the preexposure, conditioning, and test stages were conducted in a different experimental context, provides evidence for enhanced LI with a 21-day as compared with a 1-day retention interval before testing. The long retention interval potentiated the effects of stimulus-alone presentations. In Experiment 1B, in which all of the conditions were the same as those in Experiment $1 \mathrm{~A}$, except that the delay interval was spent in the home cage, test performance was not affected by length of the delay period. Together, these findings suggest that the delay-induced potentiation of stimulus-alone presentations is limited to situations in which the delay interval is spent in a context that is different from that of the other experimental stages (De la Casa \& Lubow, 2000). ${ }^{2}$ The absence of a significant three-way interaction of experiment (place of interval) $\times$ delay interval $\times$ preexposure precludes a stronger conclusion.

\section{EXPERIMENTS 2A AND 2B Extinction}

Experiments 2A and 2B were identical to Experiments 1A and $1 \mathrm{~B}$, respectively, except that there was a reversal of Stages 1 and 2. Whereas in the LI experiments (Experiments $1 \mathrm{~A}$ and $1 \mathrm{~B}$ ) the order of presentation was preexposure condition followed by conditioning, in Experiments $2 \mathrm{~A}$ and $2 \mathrm{~B}$ the conditioning stage preceded the stimulusexposure condition, thus providing an extinction procedure. As in Experiment 1, the delay period followed the second stage. Thus, in Stage 1, all groups received the saccharin-LiCl pairing. In Stage 2, half of the subjects received CS-alone trials (E condition) on each of 4 days and half received water (NE condition). Half of each group entered the Stage 3 test 1 day after extinction, and half 21 days after extinction. Thus, as in Experiments 1A and
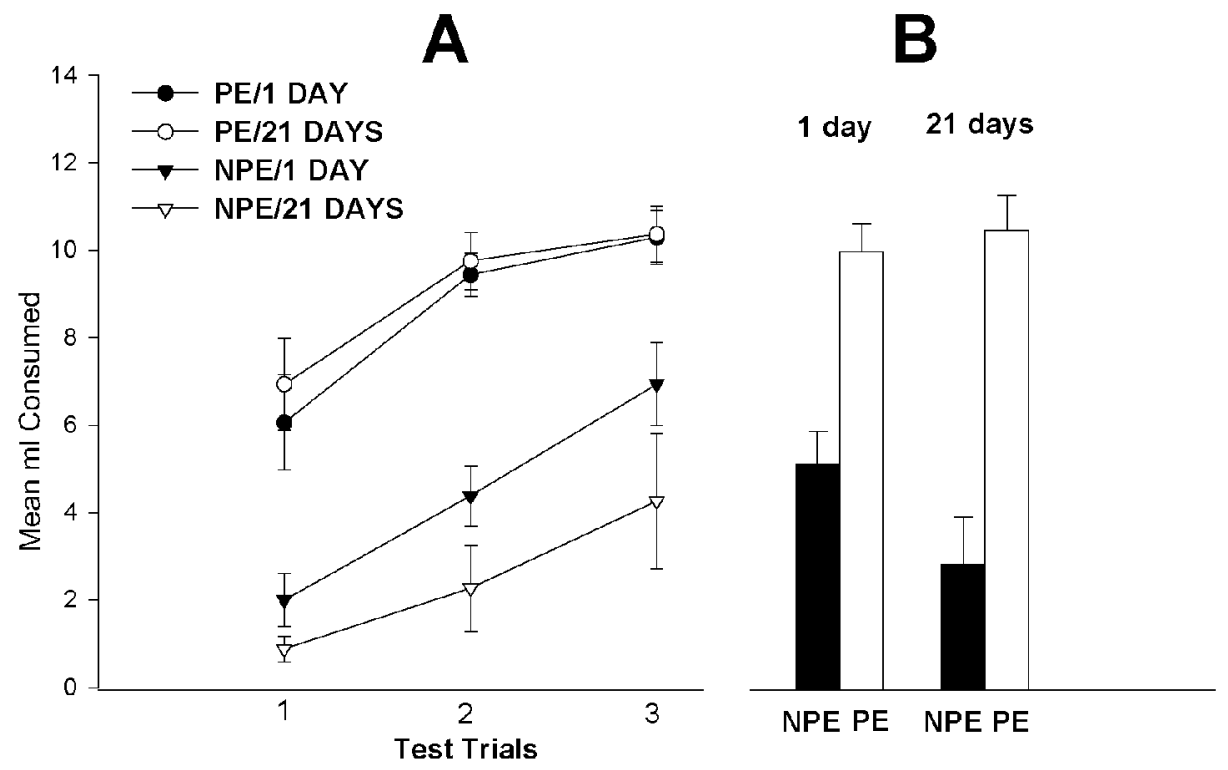

Figure 2. Experiment 1B: Mean amount of saccharin solution consumed by the four groups as a function of the three test trials (panel $A$ ) and averaged across trials (panel B). Vertical bars represent the standard errors of the mean. PE/1 day: flavor preexposed, 1-day delay; PE/21 days: flavor preexposed, 21-day delay; NPE/1 day: not preexposed to flavor, 1-day delay; NPE/21 days: not preexposed to flavor, 21-day delay. 
$1 \mathrm{~B}$, each of the two experiments comprised a $2 \times 2$ design, with two levels of stimulus preexposure (E and NE) and two levels of delay (1 day and 21 days).

Like Experiments $1 \mathrm{~A}$ and 1B, Experiments 2A and 2B differed from each other in only one respect. In Experiment $2 \mathrm{~A}$, the animals spent the delay period in a context that was different from that in which they received the CS-US, CS-alone, and test trials. In Experiment 2B, the entire experiment, including the delay interval, took place in the home cages.

Although in several studies - some with a different delay context (Brooks, Palmatier, Garcia, \& Johnson, 1999; Rosas \& Bouton, 1998) and others with the same context (Rosas \& Bouton, 1996; Schachtman, Threlkeld, \& Meyer, 2000) - spontaneous recovery of CTA has been reported, we deemed it important to investigate the effect with exactly the same parameters as those that modulate the superLI effect. If the results of Experiments $1 \mathrm{~A}$ and $1 \mathrm{~B}$ reflect an interaction between CS-alone presentations, delay length, and type of delay context, independent of the order of presentation of Stages 1 and 2, then in Experiment 2A the extinguished group that spent the long delay in a different context should consume more of the saccharin solution than should the comparable short-delay group (no spontaneous recovery). If, on the other hand, the results of Experiments $1 \mathrm{~A}$ and $1 \mathrm{~B}$ reflect an interaction between primacy factors, delay length, and type of delay context, then in Experiment 2A the extinguished group that had spent the long delay in a different context should consume less saccharin (spontaneous recovery) than should the comparable short-delay group. Given that Experiment 1B, with the delay interval spent in the same context, did not produce an interaction between stimulus preexposure and length of delay interval, neither the CS- alone exposure/ nonexposure factor nor primacy considerations provide a basis for a prediction. Nevertheless, because a number of experiments have reported spontaneous recovery in CTA preparations in which all stages, including the retention interval, were conductedin the home cage (Rosas \& Bouton, 1996, Experiments 1, 2, 3; Schachtman et al., 2000, Experiment 3 ), we expected to find such an effect, the presence of which would also allow for cross-experiment comparisons to assess the role of interval context. Ideally, this should have been accomplished in a single multifactor experiment. However, we decided that the resources required to counterbalance contexts (see note 1) would be disproportionate to the expected gain in the quality of the data.

\section{Method}

\section{Subjects}

Sixty-four male adult Wistar rats (32 in Experiment 2A, 32 in Experiment $2 \mathrm{~B}, n=8$ per group) participated in these experiments. Mean weight was $445 \mathrm{~g}$ (range, 366-523 g). The animals were fed and maintained in the same conditions as those described for Experiments $1 \mathrm{~A}$ and $1 \mathrm{~B}$.

\section{Apparatus and Procedure}

The apparatus was the same as that described for Experiments $1 \mathrm{~A}$ and $1 \mathrm{~B}$. As in Experiment 1A, in Experiment 2A all of the groups spent the delay interval in the home cage, and the remaining stages of the procedure in a different context. Similarly, in Experiment 2B, as in Experiment 1B, all stages were conducted in the home cages. Experiments $2 \mathrm{~A}$ and $2 \mathrm{~B}$ differ from their respective Experiment 1 counterparts only in terms of the relative positions of the CS-alone and the conditioning stages. In Experiments $1 \mathrm{~A}$ and $1 \mathrm{~B}$, the CSalone presentations preceded the CS-US trial, defining the LI procedure. In Experiments $2 \mathrm{~A}$ and $2 \mathrm{~B}$, the CS-alone trials were presented after the CS-US trial, a typical extinction procedure.

The experimental designs for Experiments $2 \mathrm{~A}$ and $2 \mathrm{~B}$ are summarized in the lower section of Table 1. After 7 days on a 23.5-h water-deprivation schedule, which was maintained throughout the experiment except as otherwise indicated, the animals were matched for body weight and assigned to eight groups. The first stage was conducted on Day 8, on which all the animals had access to the saccharin solution, and was followed by i.p. injections of $\mathrm{LiCl}$. The second stage was conducted on Days 9-12, with half of the animals being exposed to the saccharin solution (extinction condition, E) and half to water (nonextinction condition, NE). Testing was conducted on Days 13-15 for those groups in the 1-day delay condition, and on Days 33-35 for those groups in the 21-day delay condition. On each of the 3 test days, the subjects had access to the saccharin solution for $5 \mathrm{~min}$.

As in Experiments 1A and 1B, to equate deprivation level for all subjects at the time of testing, water was available ad lib on Days 12-20 to those animals in the 21-day condition.

\section{Results and Discussion}

\section{Experiment 2A (Different Interval Context)}

During the four postconditioningtrials, the mean amount of saccharin consumed per trial by the E groups was $1.44 \mathrm{ml}(S D=0.84)$; the NE groups consumed $5.32 \mathrm{ml}$ $(S D=2.04)$ of water. On the conditioning day, the mean amount of saccharin consumed by the four groups was $6.66 \mathrm{ml}(S D=2.09)$ for the NE/1-day group, $6.72 \mathrm{ml}$ $(S D=1.8)$ for the NE/21-day group, $7.93 \mathrm{ml}(S D=1.12)$ for the E/1-day group, and $8.24 \mathrm{ml}(S D=1.71)$ for the $\mathrm{E} / 21$-day group. There was no significant difference between groups $[F(3,28)=1.8, p>.17]$.

Figure 3 (panel A) displays the mean amount of saccharin solution consumed on each of the three test trials as a function of extinction treatment $(\mathrm{E}, \mathrm{NE})$ and delay. A mixed $3 \times 2 \times 2$ ANCOVA was performed on these data. The main factors were trials, saccharin-alone exposures (E vs. NE), and delay between second stage and test (1 vs. 21 days). Saccharin consumed on the conditioning day was the covariate. There was a main effect of trials $[F(2,56)=$ $44.78, p<.001]$, due to the progressive decrease of conditioned aversion across test trials. The trials $\times$ exposure interaction was also significant $[F(2,56)=6.76, p<.01]$, indicating, as would be expected, that extinction across test trials was faster for the E group than for the NE group [also reflected in the main E/NE effect; $F(1,27)=18.24$, $p<.001]$. None of the other interactions with trials was significant $(p s>.13)$. The between-subjects analyses revealed a significant main effect of delay $[F(1,27)=5.66$, $p<.05$ ], with the 1-day delay groups drinking more than their 21-day counterparts did. Finally, the exposure $X$ delay interaction was not significant $[F(1,27)<1]$. As can be seen in Figure 3, panel B, which presents the mean amount of fluid consumed over all test trials as a function 

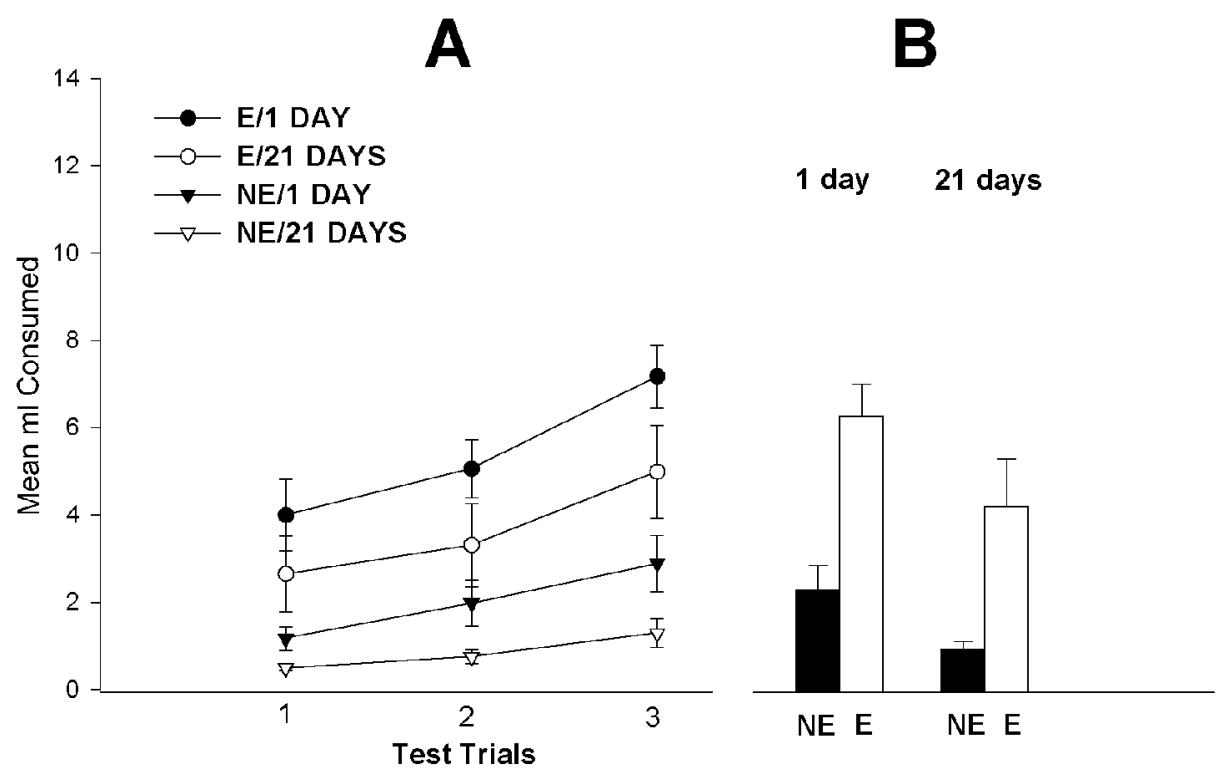

Figure 3. Experiment 2A: Mean amount of saccharin solution consumed by the four groups as a function of the three test trials (panel $A$ ) and averaged across trials (panel B). Vertical bars represent the standard errors of the mean. E/1 day: flavor exposed after conditioning, 1-day delay; E/21 days: flavor exposed, 21-day delay; NE/1 day: not exposed to flavor, 1-day delay; NE/21 days: not exposed to flavor, 21-day delay.

of exposure and delay, the E and NE groups showed a similar decrease in amount of saccharin consumed (increase in CTA) from the 1-day to the 21-day delay.

Although Figure 3 suggests that the spontaneous recovery effect was present, the difference between the E/1day group and the E/21-day group was not significant. The apparent absence of spontaneous recovery under conditions in which the retention interval was spent in a context different from that of the other stages is in opposition to findings from similar CTA experiments (Brooks et al., 1999, Experiments 1 and 2; Rosas \& Bouton, 1998). However, the latter studies did not have NE control groups. Therefore, the assessment of spontaneous recovery was made on the basis of an absolute difference between the two extinguished groups, one with a short retention interval and the other with a longer one (a procedure that discounts the possibility of interval-induced potentiation of CTA; see, e.g., Batsell \& Best, 1992, 1994), rather than on the interaction term. Nevertheless, a similar comparison in the present experiment - that between E/1 and E/ 21 -also indicates that the spontaneous recovery effect was not significant on any of the individual test trials $(p \mathrm{~s}>.09)$ or when collapsed across test trials $[F(1,32)=$ $2.52, p>$.13]. A detailed comparison between our procedures and those of Brooks et al. (1999) and Rosas and Bouton (1998), the latter two of which were basically similar, indicates two major differences. In the present experiment, animals were allowed only 5-min access to the saccharin solution on conditioning,extinction, and test trials. Brooks et al. and Rosas and Bouton (1998) allowed their subjects 15-min access to the saccharin solution. On the one hand, this might have produced stronger conditioning in their animals in comparison with ours. On the other hand, it might have generated more extinction in their animals in comparison with ours [total extinction exposure to saccharin in the present experiment was $20 \mathrm{~min}$ (5 min per day for 4 days); in theirs, it was $45 \mathrm{~min}$ and $75 \mathrm{~min}$, respectively (15 min per day for 3 days and 15 min per day for 5 days]. The latter possibility receives some support from the fact that, in the present experiment, the differences between the E/1-day group and the NE/1-day group and between the E/21-day and the NE/21-day group (see Figure 3, panel A) are relatively small and appear to increase as a function of test trials (which are also extinction trials). Consequently, the absence of a significant spontaneous recovery effect in the present experiment, in comparison with that found in other studies, may be due to our relatively weak extinction manipulation. Relatedly, the present study used male rats, whereas Brooks et al. and Rosas and Bouton (1998) used female rats. Several experiments have shown that CTA is extinguished more slowly in male than in female rats (see, e.g., Chambers, 1976; Chambers \& Sengstake, 1976).

\section{Experiment 2B (Same Interval Context)}

During the four postconditioningtrials, the mean amount of saccharin consumed per trial by the E groups was $3.85 \mathrm{ml}(S D=2.53)$; the NE groups consumed $9.15 \mathrm{ml}$ $(S D=1.17)$ of water. Mean saccharin consumption on the conditioning day was $8.02 \mathrm{ml}(S D=3.01)$ for the NE/1- 

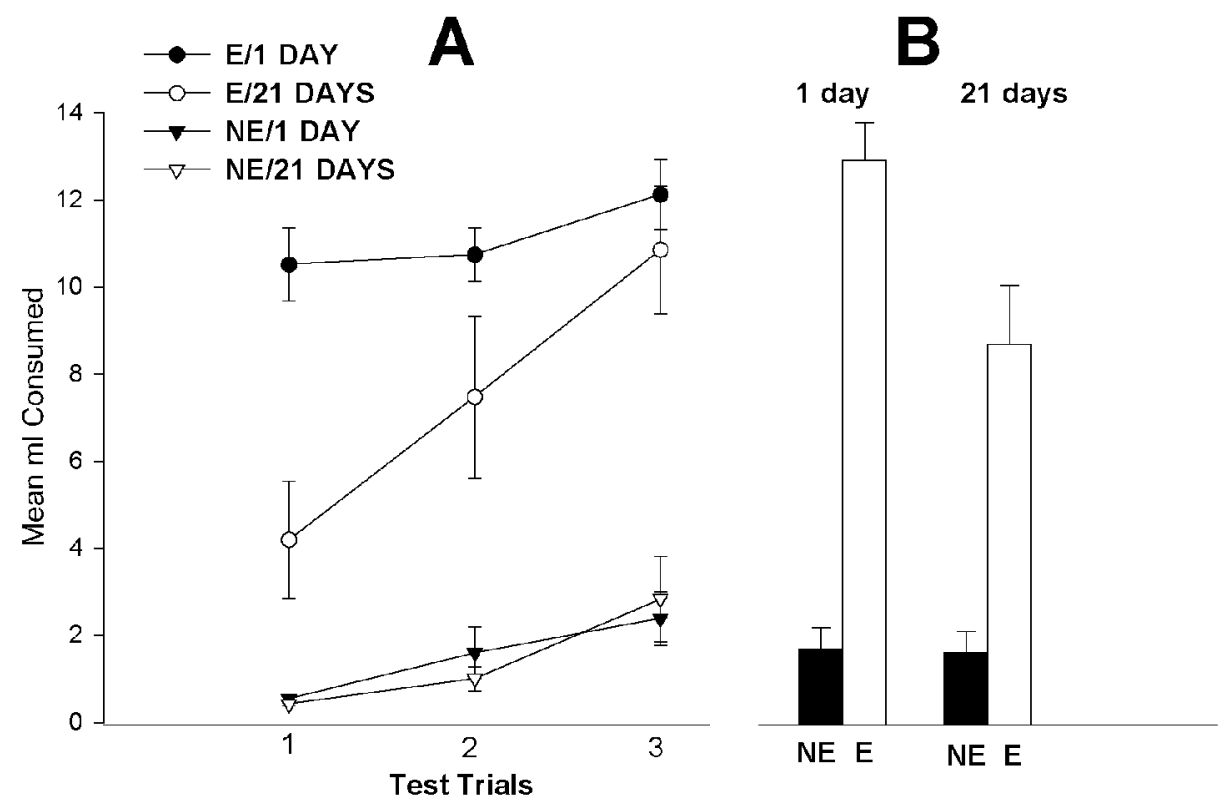

Figure 4. Experiment 2B: Mean amount of saccharin solution consumed by the four groups as a function of the three test trials (panel $A$ ) and averaged across trials (panel B). Vertical bars represent the standard errors of the mean. E/1 day: flavor exposed after conditioning, 1-day delay; E/21 days: flavor exposed, 21-day delay; NE/1 day: not exposed to flavor, 1-day delay; NE/21 days: not exposed to flavor, 21-day delay.

day group, $8.47 \mathrm{ml}(S D=3.09)$ for the NE/21-day group, $7.66 \mathrm{ml}(S D=3.3)$ for the E/1-day group, and $8.62 \mathrm{ml}$ $(S D=3.74)$ for the E/21-day group. The differences between groups were not significant $[F(3,28)<1]$.

Figure 4 ( panel A) shows the mean saccharin consumption for each of the three test trials as a function of exposure and delay. As can be seen, there was a strong spontaneous recovery of conditioned aversion in the E/21-day delay group relative to the E/1-day delay group. The $3 \times$ $2 \times 2$ ANCOVA confirmed this observation. There was a main effect of trials $[F(2,56)=18.3, p<.001]$ and a significant trials $\times$ delay interaction $[F(2,56)=3.68, p<$ $.05]$. The interaction reflects a faster rate of extinction across test trials for the 1-day delay groups in comparison with the 21-day delay groups. No other interaction with trials was significant $(p \mathrm{~s}>.08)$. The between-subjects analyses revealed significant main effects of exposure and delay $[F(1,27)=118.45, p<.001 ; F(1,27)=7.46, p<$ .05 , respectively]. The exposure $\times$ delay interaction was significant $[F(1,27)=6.3, p<.05]$, showing a clear spontaneous recovery effect in the E/21-day group. This result was confirmed by post hoc comparisons (Duncan's tests, $p<.05$ ). There were significant differences between E/1-day and E/21-day delay groups, as displayed in Figure 4 (panel B), in which the mean amount of saccharin consumption is averaged over all test days. As can be seen in Figure 4 (panel A), the spontaneous recovery effect, as reflected in the trials $\times$ exposure $\times$ delay interaction, was due primarily to the differences between the E/1-day and E/21-day delay groups on Trial $1(p<.01$; Trials 2 and 3 , $p \mathrm{~s}>.13)$.

\section{Experiments 2A and 2B Compared}

An inspection of Figures 3 and 4 appears to support the conclusions drawn from the separate analyses of Experiments $2 \mathrm{~A}$ and $2 \mathrm{~B}$-namely, that the spontaneous recovery of test-phase saccharin aversion (the difference between the 1-day and 21-day extinguished groups) was stronger with the same interval context (Experiment 2B) than with the different interval context (Experiment 2A). The complete ANCOVA, with experiments as a variable, indicated that, as in Experiments 1A and 1B, more saccharin was consumed when the delay interval was spent in the same context (Experiment 2A) than when it was spent in the different context (Experiment $2 \mathrm{~B})[F(1,55)=22.13$, $p<.001]$. This was particularly true for the extinguished groups in comparison with the nonextinguished groups (see Figures 3 and 4, B panels), as is indicated by the significant $\mathrm{E} / \mathrm{NE} \times$ experiment interaction $[F(1,55)=27.3$, $p<.001]$. Importantly, the experiment $\times$ delay $\times$ trial interaction was significant $[F(2,112)=5.41, p<.01]$, suggesting substantial spontaneous recovery on Trial 1 when the retention interval was spent in the same context (Figure 4, panel A), but not when it was spent in the different context (Figure 3, panel A). However, the experiment $X$ $\mathrm{E} / \mathrm{NE} \times$ delay interaction did not reach standard levels of significance $[F(1,55)=2.48, p=.12]$.

\section{GENERAL DISCUSSION}

The results of the two sets of experiments, albeit not their interpretation, can be summarized succinctly. When the retention interval was spent in a different context, there 
was a delay-induced super-LI effect (Experiment 1A; see Figure 1, panel B). When the interval was spent in the same context, there was no effect of delay-that is, LI effects were no different in the 1-day and 21-day delay groups (Experiment 1B; see Figure 2, panel B). On the other hand, when the LI paradigm was reversed so that, instead of CS-alone presentations preceding the conditioning episode, the CS-alone trials followed the CS-US trial, the results were markedly different. When the retention interval was spent in a different context, there was evidence neither of spontaneous recovery, which would be indicated by more CTA in the 21-day than in the 1-day delay group, nor of a superextinction effect (Experiment 2A; see Figure 3, panel B). However, when the delay interval was spent in the same delay context, there was significant spontaneous recovery (Experiment 2B; see Figure 4, panel B).

These results suggest two conclusions: (1) A different delay context supports recovery of primary-positioned CS-alone associations, super-LI. (2) In contrast to this, the same delay context supports recovery of primary-positioned CS-US events, spontaneous recovery. In both cases, then, it would appear that, with the passage of time, it is the first acquired association that is preferentially retrieved, but the conditions for retrieval enhancement are different for LI and for extinction paradigms. In the former case, the context of delay has to be different. In the latter case, given that there are a number of reports of spontaneous recovery when the interval context is different (see, e.g., Brooks et al., 1999; Rosas \& Bouton, 1998), we may conclude that same interval context potentiates such an effect.

For the moment, we will disregard the role of primacy and focus on the special nature of CS-no-consequence associations, particularly in regard to their hypersensitivity, as compared with CS-US associations, to context manipulations (for reviews, see Bouton, 1993; Bouton et al., 1999; Lubow, 1989, pp. 74-81). Why should the time-enhanced recoveries of CS-no-consequence and CS-US associations be differentially affected by the similarity of the retention interval context to that of the remaining procedural stages (same or different)? Indeed, these differential effects appear paradoxical, because normal LI is severely disrupted by a change of context across experimental stages (see, e.g., Lovibond, Preston, \& Mackintosh, 1984; Lubow, Schnur, \& Rifkin, 1976; Westbrook, Jones, Bailey, \& Harris, 2000), whereas simple conditioning is not (for a review, see Bouton, 1993; Bouton et al., 1999). The relationship of contexts between the three experimental stages (CS alone, CS-US, test) produces effects opposite to those of the relationship of the context of the interval to that of the experimental stages.

This apparent contradiction can be resolved by postulating that LI depends on the formation of a CS-noconsequence association and a higher order association with context-context-[CS-no-consequence]-such that in the test stage the context serves as a retrieval cue for the CS-no-consequence association (Lubow \& Gewirtz, 1995). Thus, in a standard LI preparation, a change of context from preexposure to test disrupts LI because the test context cannot provide a retrieval cue for the $\mathrm{CS}$-no-consequence association. On the other hand, when the contexts from preexposure to test are the same, and the long-delay interval context also is the same as that of the preexposure stage, the context-[CS-no-consequence] association is extinguished, again attenuating LI. Such LI attenuation with the same delay context has been reported in a number of CTA studies (e.g., Aguado et al., 2001, Experiment 2; Aguado et al., 1994, Experiment 1; Bakner et al., 1991) (although, for some as yet unknown reason, not in the present Experiment 1B). Although this treatment of context as an occasion setter is weakened by the fact that occasion setters are relatively resistant to extinction by mere exposure (see, e.g., Rescorla, 1986), it is important to note that occasion setting has been studied with respect to eliciting excitatory or inhibitory associations, neither of which characterizes CS-nothing associations (see, e.g., Reiss \& Wagner, 1972; Rescorla, 1971).

To account for super-LI, one has to utilize the same mechanism as that described above, but must apply it to the different delay context. The result of such an application is that the different delay context preserves the original context[CS-no-consequence] association. However, this leads to the prediction that LI magnitude would not be affected by delay when that delay is spent in a different context. To account for the delay-induced super-LI effect, an additional explanatory variable is required-namely, primacy.

CS-alone presentations and order of presentation relative to the CS-US episode (before or after CS-US, LI, and extinction procedures, respectively) interact, and the interaction is important for understanding delay-induced super-LI. Such order effects are reflected in the well known primacy principle, which asserts that first training is disproportionately stronger than subsequent training (for empirical examples, see Bouton \& King, 1986; Konorski \& Szwejkowska, 1952; Peck \& Bouton, 1990; Reed, Croft, \& Yeomans, 1996; Scavio, Ross, \& McLeod, 1983; Wickens, Tuber, \& Wickens, 1983). Konorski has also commented on the significance of primacy in regard to the transfer of excitatory responses to inhibitory responses and vice versa, as well as on a more general principle (Konorski \& Szwejkowska, 1952; also see Bouton, 1993; Lubow, 1989, p. 89; Wickens et al., 1983). Most importantly for our purposes, when first learning interferes with performance of second learning, a delay between phases increases the proactive interference effect (Bouton, 1993; Spear, 1978). As an example, Peck and Bouton (1990) sequentially conditioned two different responses in two different contexts. A return to the Phase 1 context renewed Phase 1 conditioned responding. However, this effect was stronger with a longer (28-day) than with a shorter (1-day) delay between Phase 2 and test. As they noted, such a finding is consistent with the human literature, in which proactive interference increases over long retention intervals (see, e.g., Postman, Stark, \& Fraser, 1968; Underwood, 1948).

In summary, delay-induced super-LI can be accounted for by the interaction of two factors: (1) the maintenance, 
over time, of the context-[CS-no-consequence] association by the different delay context; and (2) the potentiation of first learning, in this case CS-no-consequence, over time.

In a similar manner, one can account for spontaneous recovery in the same delay-context condition and for its absence in the different delay-context condition. Thus, in the postconditioning extinction stage, the subject learns a context-[CS-no-consequence] association. Afterwards, when the long delay interval is spent in the same context, the association with context is extinguished.Consequently, in the test stage, it is the CS-US association, which is not context dependent, that is retrieved, thereby producing more CTA - that is, leading to more spontaneous recovery-in the long- than in the short-delay group. On the other hand, when the delay context is different, there is no extinction of the context cue for retrieving CS-no-consequence, and thus no spontaneous recovery of the CS-US association.

Although it is not necessary to invoke primacy effects to explain the present set of spontaneous recovery data, the principle is certainly compatible with the effects observed with delays between extinction and retest. In general, long delay intervals, irrespective of whether the delay context is the same or different, produce a renewal of Stage 1 conditioned responding (for a review, see Bouton, 1993), suggesting enhanced recovery of the CS-US association, which, in the extinction paradigm, precedes the CS-alone presentations. In general, normal primacy effects may be obscured by short retention intervals because of their competition with recency effects. As the delay interval increases, the contribution to performance from recency would decrease, thereby providing the delay-induced potentiation of primacy.

The present set of results highlights the need to add detailed specifications to retrieval/competition and associability-deficit accounts of the effects of CS-alone presentations. Neither theoretical framework is sufficient to predict the complex pattern of reported outcomes, in that neither account allows for the special roles of length of retention interval, the relation of the interval context to the other experimental stages, and the sequencing of CSalone and CS-US episodes ( primacy), all of which appear to be necessary for predicting delay-induced super-LI and spontaneous recovery effects. Without such modifications, the present data would seem to be incompatible with Bouton's proposal that the passage of time results in a change of context and with Riccio's proposal that generalization gradients change their shape over time. In both cases, these wide-ranging statements call for major qualifications. Otherwise, they would require time to move, or stimulus generalization gradients to change, in different directions, depending on, among other things, where the time is spent!

\section{REFERENCES}

Aguado, L., De Brugada, I., \& Hall, G. (2001). Tests for inhibition after extinction of a conditioned stimulus in the flavour aversion procedure. Quarterly Journal of Experimental Psychology, 54B, 201-217.

Aguado, L., Symonds, M., \& Hall, G. (1994). Interval between preexposure and test determines the magnitude of latent inhibition: Im- plications for an interference account. Animal Learning \& Behavior, 22, 188-194.

Álvarez, R., \& LóPez, M. (1995). Effects of elements or compound preexposure on conditioned taste aversion as a function of retention interval. Animal Learning \& Behavior, 23, 391-399.

Bakner, L., Strohen, K., Nordeen, M., \& Riccio, D. C. (1991). Postconditioning recovery from the latent inhibition effect in conditioned taste aversion. Physiology \& Behavior, 50, 1269-1272.

BATSELL, W. R., JR., \& BEST, M. R. (1992). Variations in the retention of taste aversions: Evidence for retrieval competition. Animal Learning \& Behavior, 20, 146-159.

BAtSELL, W. R., JR., \& BeST, M. R. (1994). The role of US novelty in retention interval effects in single-element taste-aversion learning. Animal Learning \& Behavior, 22, 332-340.

Bouton, M. E. (1993). Context, time, and memory retrieval in the interference paradigms of Pavlovian learning. Psychological Bulletin, 114, 80-99.

Bouton, M. E., \& KING, D. A (1986). Effect of context on performance to conditioned stimuli with mixed histories of reinforcement and nonreinforcement. Journal of Experimental Psychology: Animal Behavior Processes, 12, 4-15.

Bouton, M. E., Nelson, J. B., \& Rosas, J. M. (1999). Stimulus generalization, context change, and forgetting. Psychological Bulletin, 125, 171-186.

Brooks, D. C., Palmatier, M. I., Garcia, E. O., \& Johnson, J. L. (1999). An extinction cue reduces spontaneous recovery of a conditioned taste aversion. Animal Learning \& Behavior, 27, 77-88.

Chambers, K. C. (1976). Hormonal influences on sexual dimorphism in rate of extinction of a conditioned taste aversion in rats. Journal of Comparative \& Physiological Psychology, 90, 851-856.

Chambers, K. C., \& Sengstake, C. B. (1976). Sexually dimorphic extinction of a conditioned taste aversion in rats. Animal Learning \& Behavior, 4, 181-185.

Channell, S., \& Hall, G. (1981). Facilitation and retardation of discrimination learning after exposure to the stimuli. Journal of Experimental Psychology: Animal Behavior Processes, 7, 437-446.

De la CASA, L. G., \& Lubow, R. E. (1995). Latent inhibition in conditioned taste aversion: The roles of stimulus frequency and duration, and amount of fluid ingested during preexposure. Neurobiology of Learning \& Memory, 64, 125-132.

De LA CASA, L. G., \& Lubow, R. E. (2000). Super-latent inhibition with conditioned taste aversion testing. Animal Learning \& Behavior, 28, 389-399.

De la Casa, L. G., \& Lubow, R. E. (2002). An empirical analysis of the super-latent inhibition effect. Animal Learning \& Behavior, 30, 112120.

FANSELOW, M. S. (1990). Factors governing one-trial contextual conditioning. Animal Learning \& Behavior, 18, 264-270.

Hall, G., \& Channell, S. (1986). Context specificity of latent inhibition in taste aversion learning. Quarterly Journal of Experimental Psychology, 38B, 121-139.

HALl, G., \& Minor, H. (1984). A search for context-stimulus associations in latent inhibition. Quarterly Journal of Experimental Psychology, 36B, 145-169.

Kaye, H., Preston, G. C., Szabo, L., Druiff, H., \& Mackintosh, N. J. (1987). Context specificity of conditioning and latent inhibition: Evidence for a dissociation of latent inhibition and associative interference. Quarterly Journal of Experimental Psychology, 39B, 127-145.

Killcross, A. S., Kiernan, M. J., Dwyer, D., \& Westbrook, R. F. (1998). Loss of latent inhibition of contextual conditioning following nonreinforced context exposure in rats. Quarterly Journal of Experimental Psychology, 51B, 75-90.

Konorski, J., \& SzWEJKowsKa, G. (1952). Chronic extinction and restoration of conditioned reflexes: IV. The dependence of the course of extinction and restoration of conditioned reflexes on the "history" of the conditioned stimulus (the principle of the primacy of the training). Acta Biologiae Experimentalis, 16, 95-113.

Lovibond, P. F., Preston, G. C., \& Mackintosh, N. J. (1984). Context specificity of conditioning, extinction, and latent inhibition. Journal of Experimental Psychology: Animal Behavior Processes, 10, 360375 . 
LuBow, R. E. (1989). Latent inhibition and conditioned attention theory. New York: Cambridge University Press.

Lubow, R. E., \& GEwIRTz, J. C. (1995). Latent inhibition in humans: Data, theory, and implications for schizophrenia. Psychological Bulletin, 117, 87-103.

Lubow, R. E., Schnur, P., \& Rifkin, B. (1976). Latent inhibition and conditioned attention theory. Journal of Experimental Psychology: Animal Behavior Processes, 2, 163-174.

Lubow, R. E., Weiner, I., \& Schnur, P. (1981). Conditioned attention theory. In G. H. Bower (Ed.), The psychology oflearning and motivation (Vol. 15, pp. 1-49). New York: Academic Press.

Mackintosh, N. J. (1975). A theory of attention: Variations in the associability of stimuli with reinforcement. Psychological Review, 82 , 276-298.

Miller, R. R, Kasprow, W. J., \& Schachtman, T. R. (1986). Retrieval variability: Sources and consequences. American Journal of Psychology, 99, 145-218.

Miller, R. R., \& MAtzel, L. D. (1988). The comparator hypothesis: A response rule for the expression of associations. In G. H. Bower (Ed.), The psychology of learning and motivation (Vol. 22, pp. 51-92). San Diego: Academic Press.

Pearce, J. M., \& Hall, G. (1980). A model for Pavlovian conditioning: Variations in the effectiveness of conditioned but not unconditioned stimuli. Psychological Review, 87, 332-352.

Peck, C. A., \& Bouton, M. E. (1990). Context and performance in aversive-to-appetitive and appetitive-to-aversive transfer. Learning \& Motivation, 21, 1-31.

Postman, L., Stark, K., \& Fraser, J. (1968). Temporal changes in interference. Journal of Verbal Learning \& Verbal Behavior, 7, 672-694.

Reed, P., Croft, H., \& Yeomans, M. (1996). Rats' memory for serially presented novel flavours: Evidence for non-spatial primacy effects. Quarterly Journal of Experimental Psychology, 49B, 174-187.

REISS, S., \& WAGNER, A. R. (1972). CS habituation produces "latent inhibition" effect but no active "conditioned inhibition." Learning \& Motivation, 3, 237-245.

RESCORLA, R. A. (1971). Summation and retardation tests of latent inhibition. Journal of Comparative \& Physiological Psychology, 75, 77-81.

Rescorla, R. A. (1986). Extinction of facilitation. Journal of Experimental Psychology: Animal Behavior Processes, 12, 16-24.

Riccio, D. C., Ackil, J., \& Burch-Vernon, A. (1992). Forgetting of stimulus attributes: Methodological implications for assessing associative phenomena. Psychological Bulletin, 112, 433-445.

Riccio, D. C., Rabinowitz, V. C., \& Axelrod, S. (1994). Memory: When less is more. American Psychology, 49, 917-926.

Riccio, D. C., Richardson, R., \& Ebner, D. L. (1984). Memory retrieval deficits based upon altered contextual cues: A paradox. Psychological Bulletin, 96, 152-165.

Rosas, J. M., \& Bouton, M. E. (1996). Spontaneous recovery after extinction of a conditioned taste aversion. Animal Learning \& Behavior, 24, 341-348.

Rosas, J. M., \& Bouton, M. E. (1998). Context change and retention interval can have additive, rather than interactive, effects after taste aversion extinction. Psychonomic Bulletin \& Review, 5, 79-83.

Rudy, J. W., Barrientos, R. M., \& O'Reilly, R. C. (2002). Hippocampal formation supports conditioning of memory of a context. Behavioral Neuroscience, 116, 530-538.

Scavio, M. J., Ross, R. T., \& McLeod, L. M. (1983). Preservation of associative strength in rabbit nictitating membrane response conditioning. Animal Learning \& Behavior, 11, 91-94.
Schachtman, T. R., Threlkeld, R., \& Meyer, K. (2000). Retention of conditioned inhibition produced by extinction. Learning \& Motivation, 31, 283-300.

SPEAR, N. E. (1978). The processing of memories: Forgetting and retention. Hillsdale, NJ: Erlbaum.

UNDERWOOD, B. J. (1948). Retroactive and proactive inhibition after five and forty-eight hours. Journal of Experimental Psychology, 38, 29-38.

WAGNER, A. R. (1981). SOP: A model of automatic memory processing in animal behavior. In N. E. Spear \& R. R. Miller (Eds.), Information processing in animals: Memory mechanisms (pp. 5-47). Hillsdale, NJ: Erlbaum.

Westbrook, R. F., Jones, M. L., Bailey, G. K., \& Harris, J. A. (2000). Contextual control over conditioned responding in a latent inhibition paradigm. Journal of Experimental Psychology: Animal Behavior Processes, 26,157-173.

Wickens, C., Tuber, D. S., \& Wickens, D. D. (1983). Memory for the conditioned response: The proactive effect of preexposure to potential conditioning stimuli and context change. Journal of Experimental Psychology: General, 112, 41-57.

Zalstein-Orda, N., \& Lubow, R. E. (1995). Context control of negative transfer induced by preexposure to irrelevant stimuli: Latent inhibition in humans. Learning \& Motivation, 26, 11-28.

\section{NOTES}

1. Given that the analysis was conducted on data from separate experiments, conclusions drawn from it should be accepted with caution.

2. It should be evident from the description of the delay-context manipulation that the "same"-"different" distinction is confounded with other factors. The set of procedures for obtaining delay-induced super$\mathrm{LI}$ can be characterized as A-A-H-A. The first A represents the preexposure stage; the second $\mathrm{A}$, the conditioning stage; $\mathrm{H}$, the home cage; and the fourth $\mathrm{A}$, the test stage. Thus, $\mathrm{A}-\mathrm{A}-\mathrm{H}-\mathrm{A}$, but not $\mathrm{H}-\mathrm{H}-\mathrm{H}-\mathrm{H}$, generated super-LI. In A-A-H-A, although $\mathrm{H}$ is a unique context relative to A, it is also a familiar home cage. An empirical answer as to whether it is uniqueness or familiarity that is critical requires a counterbalanced design that omits the home cage from the manipulations (AAAA, AABA, BBBB, BBAB).

We contend that the critical element for producing super-LI is the uniqueness, and not the familiarity, of the delay context, uniqueness being defined in terms relative to the preexposure, conditioning, and test contexts. Studies that have independently manipulated context change and context familiarity (Channell \& Hall, 1981, Experiment 3; Hall \& Channell, 1986, Experiment 3; Hall \& Minor, 1984; Kaye, Preston, Szabo, Druiff, \& Mackintosh, 1987; Lovibond, Preston, \& Mackintosh, 1984;Zalstein-Orda \& Lubow, 1995) all revealed that LI was dependent on conjoint stimulus-context preexposure. In other words, context familiarity per se does not affect LI. This indicates that super-LI also would be independent of the mere familiarity of the delay context. In contrast, there is evidence that familiarity of the training context may affect stimulus control, as in the enhancement of fear contextual conditioning by prior exposure to the context (see, e.g., Fanselow, 1990; Rudy, Barrientos, \& O’Reilly, 2002).

(Manuscript received May 2, 2002; revision accepted for publication August 14, 2002.) 